\title{
Spatial and temporal variations in women undernutrition in Ethiopia- A multilevel analysis.
}

\author{
Fikrewold Bitew, Samuel H. Nyarko \& Corey S. Sparks \\ Department of Demography, College of Public Policy, \\ The University of Texas at San Antonio, USA \\ Email: fikrewold.bitew@utsa.edu; fikre.wold@gmail.com
}

\begin{abstract}
Background: Women's undernutrition is a major concern in many sub-Saharan African countries including Ethiopia; however, little information exists on its spatial and temporal variation within a single national context. This paper examines spatial and temporal variations in women's undernutrition and its determinants in Ethiopia between 2000 and 2016.

Data source and methods: We use data from the Ethiopia Demographic and Health Surveys from 2000 to 2016 . We used multilevel logistic regression models with region-level random effects to estimate determinants of undernutrition.

Results: The results show substantial regional variations in women's undernutrition in Ethiopia, which show mixed patterns over time. Also, the regional variations are significantly affected by age, education level, marital status, wealth, occupational status and type of residence as well as some aggregate factors. Undernutrition risks are considerably higher for teenage women, no education, never-married, unemployed, and rural women, as well as women from poor households than their counterparts. Additionally, in regions with lower levels of women's education, the risk of undernutrition was higher.

Conclusions: Regional variations in women's undernutrition in Ethiopia are significantly determined by individual sociodemographic, economic and community level characteristics. Policy decisions should focus on bridging the regional disparities in the country, especially in areas that have made little progress in reducing women's undernutrition.
\end{abstract}

Keywords: Spatial variations, women undernutrition, Ethiopia.

\section{Introduction}

Undernutrition is a global challenge as it is a direct cause for millions of deaths in the world every year (Ahmed, Hossain, \& Sanin, 20I2; CSA, \& ICF, 2016; FAO, WFP, \& IFAD, 20I2). About 795 million people are undernourished globally, which is over 167 million increase during the last decade (FAO et al, 20/2). Women, infants, and young children are among the most nutritionally-vulnerable groups (Lartey, 2008). Maternal and child undernutrition is the underlying reason for 3.5 million deaths, $35 \%$ of the disease burden in children younger than 5 years and II\% of total global disability-adjusted life years (Black, Devereux, \& Salvanes, 2005).

A serious problem of women's undernutrition is evident in most countries in sub-Saharan Africa (SSA), south-central and southeastern Asia, and in Yemen, where more than $20 \%$ of women have a body-mass index of less than $18.5 \mathrm{~kg} / \mathrm{m}^{2}$ (Black et al., 20I3). SSA is home of the most nutritionally insecure people in the world (Fanzo, 20I2; Sahn and Alderman, 1998). While it has decreased significantly in most other developing countries in the last decade, malnutrition prevalence has been nearly static in SSA (Sharma et 4727 al., 2017). The prevalence of undernutrition in Ethiopia is one of the highest compared to other subSaharan African countries (Uthman, 2009). Approximately, one in every four $(27 \%)$ of Ethiopian women of reproductive age are undernourished (CSA, \& ICF, 20I2), twice the SSA average of $13.3 \%$ (Mukuria, Aboulafia, \& Themme, 2005). Much research has shown the effect of various individuallevel characteristics on women's undernutrition in different SSA countries including Ethiopia (Bitew and Telake, 2010; Tebekaw et al., 2014). Nonetheless, the temporal and between-region variations that are highly related to women's undernutrition in Ethiopia have not been nationally investigated so far albeit this has been done in other developing country settings (Mohsena, Goto, \& Mascie-Taylor, 2015). On the contrary, many studies rather focused on women's undernutrition in specific regions or cities in the country (Ferede, Lemessa, Tafa, \& Sisay, 2017; Gedle, Gelaw, Muluye, \& Mesele, 2015; Tebekaw, Teller, \& Colón-Ramos, 20I4), while some also lack temporal aspect (Bitew \& Telake, 20I0). This study seeks to fill that literature gap by providing both the 
spatial and temporal context on women's undernutrition in Ethiopia using nationally representative data sets. This is important because it provides our understanding of the spatio-temporal dynamics of women's undernutrition in Ethiopia and how these can be explained by the individual and aggregate level characteristics within the country. In this regard, the study sought to provide answers to two main research questions: how does women's undernutrition vary among the regions of Ethiopia over time? Are the regional variations in women's undernutrition over time determined by the individual and aggregate level characteristics of women?

\section{Literature review}

Several individual-level factors have been linked to the risk of women's undernutrition in SSA, ranging from demographic to socio-economic characteristics. However, it is important to note that only a limited number of studies have examined women's undernutrition in SSA so far. Demographic characteristics such as age and marital status have been strongly linked to women's undernutrition by the few extant studies (Babalola, 2017; Caputo, Foraita, Klasen, \& Pigeot, 2003; Mtumwa, Paul, \& Vuai, 2016; O. A. Uthman \& Aremu, 2008). For instance, Bitew and Telake (2010) and Mtumwa et al. (2016) used the Demographic and Health Survey data to examine determinants of women's undernutrition in Ethiopia and Tanzania, respectively, and they observed that age and marital status have a considerable effect on women's undernutrition. It is evident that younger women (15-19 years) have increased risk of undernutrition (Bitew \& Telake, 20l0; Mtumwa et al., 2016), while never-married and widowed women also have a considerably higher risk of undernutrition (Caputo et al., 2003; Mtumwa et al., 20l6; O. A. Uthman \& Aremu, 2008).

Aside from these factors, socio-economic inequalities are also found to have a considerable effect on women's undernutrition (Mtumwa et al., 2016; Olalekan A Uthman, 2009). Inequalities in educational attainment and occupational status have significant effect on women nutritional status, where women with advanced educational level and women who work in non-manual or professional jobs are at a substantially lower risk of undernutrition (Bitew \& Telake, 2010; Mtumwa et al., 2016) than their counterparts without formal education or who are unemployed. Ultimately, household wealth inequalities have been found to have some direct effects on women's undernutrition (Hong \& Hong, 2007; Mtumwa et al., 2016). Previous work has also shown the importance of community or regionallevel socioeconomic status on both maternal and child nutritional status and mortality (Chodhury et al., 2016, Haile et al., 2016, Adedini et al., 2015). Nonetheless, it is apparent in the literature that the direct effect of economic inequalities on women's undernutrition is not adequately examined in subSaharan Africa in general and for the Ethiopian case, specifically. A notable aspect of these studies is their general lack of spatial, vis a vis regional, and temporal variations in women's undernutrition which prevents us from understanding the dynamics of undernutrition over time. Moreover, these studies did not use any multilevel approach to achieve their aims; rather, drew on only single level approaches to examine the effect of individual-level factors on women's undernutrition. Based upon work from other developing nation settings both in SSA and in other areas of the world, community and regional characteristics are associated with maternal and child health. Consequently, it is not possible to understand how both individual and aggregate level factors explain considerable variations in women's undernutrition. Outside SSA, Hong and Hong (2007) as well as Kamal and Islam (20I0) using a single wave of demographic and health survey data also provide evidence that household wealth inequalities independently affect the nutritional status of women in Asia. They indicate that women from the poorest households are increasingly likely to be undernourished compared to women from the richest households (Hong \& Hong, 2007; Kamal \& Islam, 2010). This has vital implications for poverty alleviation in developing countries including Ethiopia. This paper bridges the literature gaps by providing knowledge on the regional variations in women's undernutrition over time and using a multilevel modeling approach to estimate the individual and aggregate factors underlining the regional variations in Ethiopia.

\section{Data and methods}

This study uses data from the Ethiopian Demographic and Health Surveys (DHS). The comparative nature of DHS data, along with the availability of Body Mass Index (BMI) data that can be linked to individual-level survey data, provides the chance for a populationbased study of factors associated with undernutrition. Our analysis is therefore based on the data from DHS surveys collected during (between 2000 and 2016) from a total of II regions. The sample is therefore limited to $(7,767$ in $2000 ; 5,640$ in $2005 ; 11,919$ in 20II; and 8,220 in 2016) non-pregnant women aged 15 to 49 years with valid Body Mass Index (BMI $\mathrm{kg} / \mathrm{m}^{2}$ ). This paper uses BMI as a measure of undernutrition. Based on the WHO recommendations, women with $\mathrm{BMI}<\mid 8.5$ are considered as underweight (Barba, Cavalli-Sforza, 
Cutter, \& Darnton-Hill, 2004). Details of the sampling design and data collection procedures for each survey are available in the individual country DHS reports (CSA, 2016).

\section{Study variables}

Based on the WHO recommendation, women aged I5-49 whose BMI is less than 18.5 are considered underweight or undernourished. Based on this, the outcome variable in this analysis is women's undernutrition measured as a binary outcome with women having $\mathrm{BMI}<\mid 8.5$ recoded as I or else 0 . The predictors include sociodemographic characteristics such as age (15-19, 20-29, 30-39, and 40-49); parity per women $(0,1-2,3-4,5+)$, marital status (never married, married or in union, widowed and divorced/separated), educational level (no education, primary, secondary or higher), occupation (not working, professional/sales/service, agriculture/domestic/manual), wealth-index and place of residence (urban or rural). In this study, wealthindex was derived from a set of correlated variables such as source of water, electricity, quality of roofing and floor material, quality of wall and floor, and ownership of material possessions (e.g., television, radio, car, bicycle, refrigerator, motorcycle, telephone) using principal components analysis (PCA). A wealth index score is assigned for each woman based on the weighted combination of characteristics and assets in their household with the weights derived from Principal Component Analysis (PCA) procedure (Jolliffe \& Cadima, 20I6), as applied by Habyarimana, Zewotir, and Ramroop (2015) in a study in Rwanda. For each survey year, the sample was divided into five categories from richest to poorest along with the resulting standardized index which was collapsed into three categories; low, medium and high. Other predictors included in the analysis include a region-level variable for each year in the analysis, measuring the proportion of women with secondary education in the region. In order to measure the overall trend in undernutrition, we also include survey year (Time) as a continuous variable.

\section{Analytical procedure}

The R statistical package ( $R$ Core Team, 20I8) was used for all data processing and analysis. Multilevel logistic regression models were used to examine the effects of individual and region-level predictors on women's undernutrition status. This analysis is specified as a two-level model, with women nested within regions over time, and variables include individual and regional level predictors. All models are estimated using a Bayesian modeling framework using the brms package (Burkner, 2017) in R and the Stan modeling language (Carpenter et al., 2017).
Three regression models were estimated. All three models are specified as multilevel logistic regression models, with the region of residence as the higherlevel unit. A random slope for time within regions was also added to the models to examine whether time trends vary among the regions over the study period. The model is specified as below:

logit(Undernutrition ${ }_{\mathrm{ij}}$ )

$$
\begin{array}{r}
=\beta_{0 \mathrm{j}}+\sum \beta \mathrm{x}_{\mathrm{i}}+\gamma \mathrm{z}_{\mathrm{j}}+v_{\mathrm{j}} \\
* \text { Year } \\
\beta_{0 j}=\beta_{0}+u_{j}, \text { with } u_{j} \sim \operatorname{Normal}\left(0, \sigma_{u}\right) \\
v_{j}=v_{0}+v_{j}, \text { with } v_{j} \sim \operatorname{Normal}\left(0, \sigma_{v}\right)
\end{array}
$$

Where $i$ references the woman, and $j$ references the region, $\beta_{0 j}$ is the region random intercept term, $v_{0}$ is the overall time trend within the country, and $v_{j}$ is the time trend within each region, modeled as random slopes for the $j$ regions, the $\beta x_{i}$ term includes all the individual level covariates, and the $\gamma z_{j}$ term is the regression effects for the region-level maternal education variable.

Model $I$ is specified as a baseline model to understand the amount of between region variation over time, and has no individual or region-level covariates, and only the time random slopes and the region level random intercepts, Model 2 added controls for individual-level sociodemographic factors and Model 3 comprised the full model which further controlled for aggregate level variable, the proportion of women in each region, in each time, with a secondary education.

Since a Bayesian modeling strategy is used, all model parameters are given prior distributions according to recommended best practices (Burkner, 2017; Gelman 2004; Gelman et al., 2015; Gelman et al., 2017). Flat priors are assigned to all of the population level parameters $\left(\beta_{0}, v_{0}, \beta, \gamma\right)$, region level variances $\left(\sigma_{u}, \sigma_{v}\right)$ are given half Student t priors. Two independent Markov chains were used, and models were burned in for 1,500 iterations, followed by 2,500 iterations for sampling of the parameters. Models showed signs of convergence with all model parameters having Rhat values of I (Gelman and Rubin, 1992). Models are summarized in terms of the odds ratios, calculated from the posterior means of the regression parameters and $95 \%$ Bayesian credible intervals.

\section{Results}

\section{Descriptive results}

The percentage distribution of non-pregnant women aged 15-49 per selected sociodemographic characteristics is presented in Table I. On average, about $36 \%$ of the total respondents were in the age 
group of 20-29 whereas about 16\% were in ages 40 49 for the study period. More than half $(56.1 \%)$ of the respondents were married women, and $31 \%$ were never married while the rest were either widowed or divorced. The majority of the total respondents have ever had a child with about onequarter $(24.4 \%)$ having 5 or more children. Also, more than half $(57.3 \%)$ of the total respondents were from rural settings, and they represented the majority across all the survey years (Tablel). In total, close to half $(47.9 \%)$ of the respondents had no formal education with a little more than one-fifth (22.2\%) having secondary school or higher education, even though the majority of them were formally uneducated in 2000 (66.6\%) and 2005 $(64.3 \%)$. About $40 \%$ of the total respondents were from poor households while $38.6 \%$ were from rich households. Close to half (48.2\%) were unemployed while more than one-fifth (23.8\%) were professionally employed women.

Table I: Percentage of women by background characteristics, EDHS (2000 - 2016)

\begin{tabular}{cccccc}
\hline Background variables & 2000 & 2005 & $20 I I$ & 2016 & Total \\
& $(n=7767)$ & $(n=5,640)$ & $(n=1 I, 919)$ & $(n=8,608)$ & $(n=33,934)$ \\
\hline
\end{tabular}

Age

15-19

20-29

30-39

40-49

Marital Status

Never married

29.7

Married

56.1

Widowed

Divorced/separated

Parity

0

\section{I-2}

3-4

$5+$

Type of residence

Rural

68

Urban

32

29.2

4

10.2

36.4

32.3

19.1

16.9

31.7

80.9

19.1

66.6

64.3

18.4

14.2

0.8

Higher

Secondary

Wealth Index

24.7

34.4

7.4

26.9

Education

No education
Primary
Secondary
Higher

1.5

24.9

23.7

24.2

35.6

33.7

35.8

23.9

26.8

24.1

15.6

15.8

15.9

29.7

30.1

31.0

59.3

59.1

56.3

3.3

3

3.9

7.6

7.8

8.8

35.1

36.7

37.3

20.6

21.6

22.6

16.8

16

15.7

27.5

25.7

24.4

71.4

65.2

57.3

28.6

34.8

42.7 


$\begin{array}{llllll}\text { Poor } & 53.4 & 52.4 & 43.9 & 53.4 & 40.3 \\ \text { Middle } & 24.8 & 23.0 & 28.6 & 20.9 & 21.1 \\ \text { High } & 21.8 & 24.6 & 27.5 & 25.7 & 38.6 \\ \text { mployment Status } & & & & \\ \begin{array}{l}\text { Unemployed } \\ \text { Non-manual/ }\end{array} & 37.2 & 64.7 & 42.1 & 44.4 & 48.2 \\ \begin{array}{l}\text { Professional } \\ \text { Agricultural/Manual }\end{array} & 19.1 & 12.6 & 22.2 & 23.1 & 23.8 \\ \text { (skilled/unskilled) } & 43.7 & 22.6 & 35.7 & 32.6 & 28.0\end{array}$

Regional and temporal variation in women's undernutrition

The regional percentage variation of women's undernutrition in Ethiopia from the year 2000 to the year 2016 is presented in Figure I. For 2000, the prevalence of women's undernutrition was highest for the regions of Tigray, Gambela, Ben-Gumuz, Somali (between $32 \%$ and $44 \%$ ) while for the rest of the regions it ranged between $26 \%$ and $32 \%$. Likewise, in 2005, women's undernutrition was more prevalent in Tigray, Afar, Somali, Gambela regions but was less prevalent for the remaining regions (at least $21 \%$ ). Women's undernutrition in 2011 was most prevalent in the Tigray and Afar regions (between $32 \%$ and $44 \%$ ) compared with the rest of the regions, while SNNP? had the least prevalence (up to $21 \%$ ). In 2016, however, only the Afar region had the most prevalence of women's undernutrition with the remaining regions seeing considerable reductions while Ben-Gumuz and SNNP had the least prevalence.

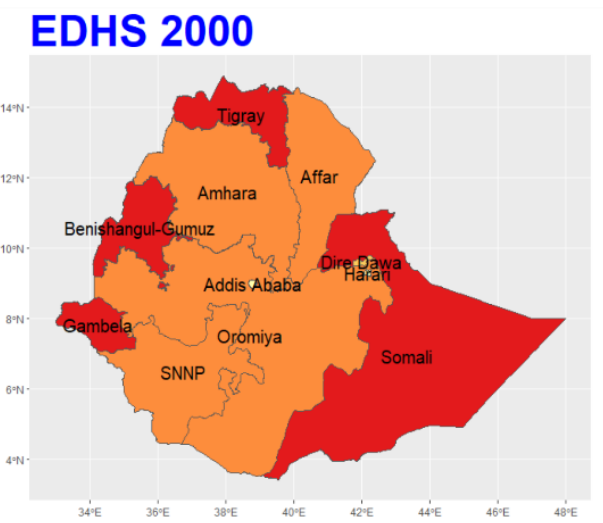

EDHS 2011

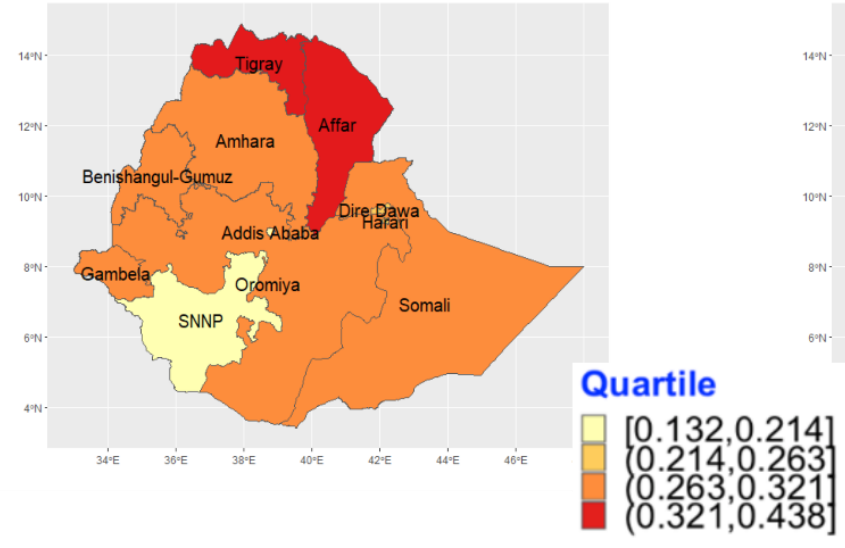

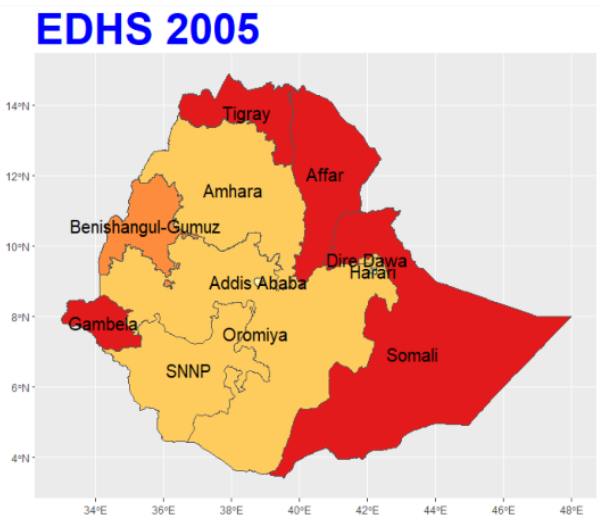

EDHS 2016

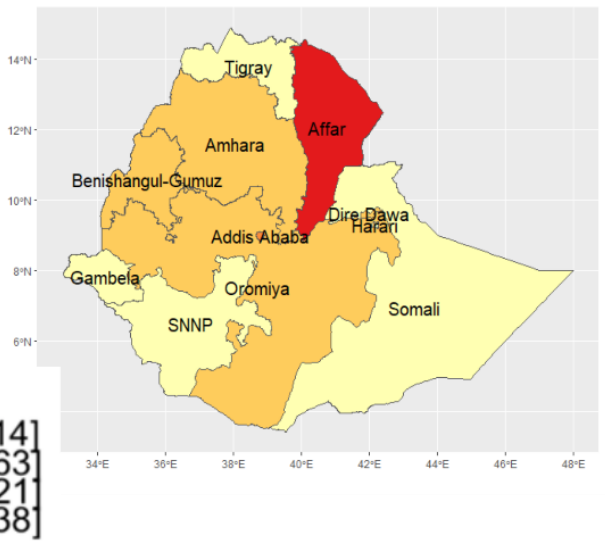

Figure 1: Proportion of Women Underweight in Ethiopia by Region (EDHS 200-2016) 
Multilevel regression analysis of women's undernutrition in Ethiopia

the variables and their $95 \%$ Bayesian credible Table 2 presents the results from the multilevel intervals are reported. Significance is indicated at the logistic regression models. Odds ratios for each of

Table 2: Results for multi-level random slope logistic regression models of women undernutrition.

\begin{tabular}{llll}
\hline Model I & Model 2 & Model 3 \\
\hline Odds Ratio (95\% & Odds Ratio (95\% & Odds Ratio (95\% \\
BCl) & $\mathrm{BCl})$ & $\mathrm{BCl})$
\end{tabular}

\section{Parameter}

Year

$0.87(0.7-1.06)$

$0.86(0.72-1.03)^{*}$

$0.89(0.76-1.02)^{*}$

Age (Ref: 15-19)

20-29

30-39

40-49

Parity (Ref: 0)

I to 2

3 to 4

$5+$

Marital Status (Ref: Never

Married)

Married

Widowed

Divorced/Separated

Education Level (Ref: No education)

Primary

Secondary

Higher

Wealth Index (Ref: Poor)

Middle

High

$$
\begin{array}{ll}
1.06(0.99-1.14)^{*} & 1.07(1-1.15)^{* *} \\
0.84(0.75-0.94)^{* *} & 0.85(0.76-0.94)^{* *} \\
0.88(0.73-1.03) & 0.9(0.76-1.06)
\end{array}
$$

Occupation (Ref: Not employed)

Non-manual/Professional

Agricultural/Manual

(Skilled/unskilled)

$$
0.84(0.79-0.9)^{* *} \quad 0.84(0.78-0.91)^{* *}
$$
$0.92(0.86-0.98)^{* * *}$
$0.91(0.86-0.98)^{* * *}$
$0.7(0.63-0.79)^{* *}$
$0.73(0.64-0.81)^{* * *}$

$0.87(0.82-0.92)^{* *} \quad 0.87(0.82-0.92)^{* *}$ 
Place of Residence

(Ref: Rural)

Urban

$0.73(0.66-0.81)^{* *}$

$0.74(0.67-0.82)^{* * *}$

Proportion of Secondary Education

Variance Components

Intercept (Region)

$0.12(0.04-0.35)$

$0.10(0.04-0.3)$

$0.12(0.04-0.35)$

Slope (Year by Region)

$0.11(0.04-0.34)$

$0.07(0.02-0.22)$

$0.05(0.01-0.18)$

WAIC

35546.3

34732.8

34709.4

OR: Odds Ratios; Significant at $*<0.1, * *<0.05$

Model I estimates the overall time trend of women's undernutrition within the regions. While the overall time trend suggests that the odds of undernutrition decreases (odds ratio < I), the model parameter was not significant. There were large variances between regions and in the time trends across regions, as identified by the variance terms for region and year within region.

Using Model I, we illustrate the between region time trends implied by the model. These are presented in Figure 2.

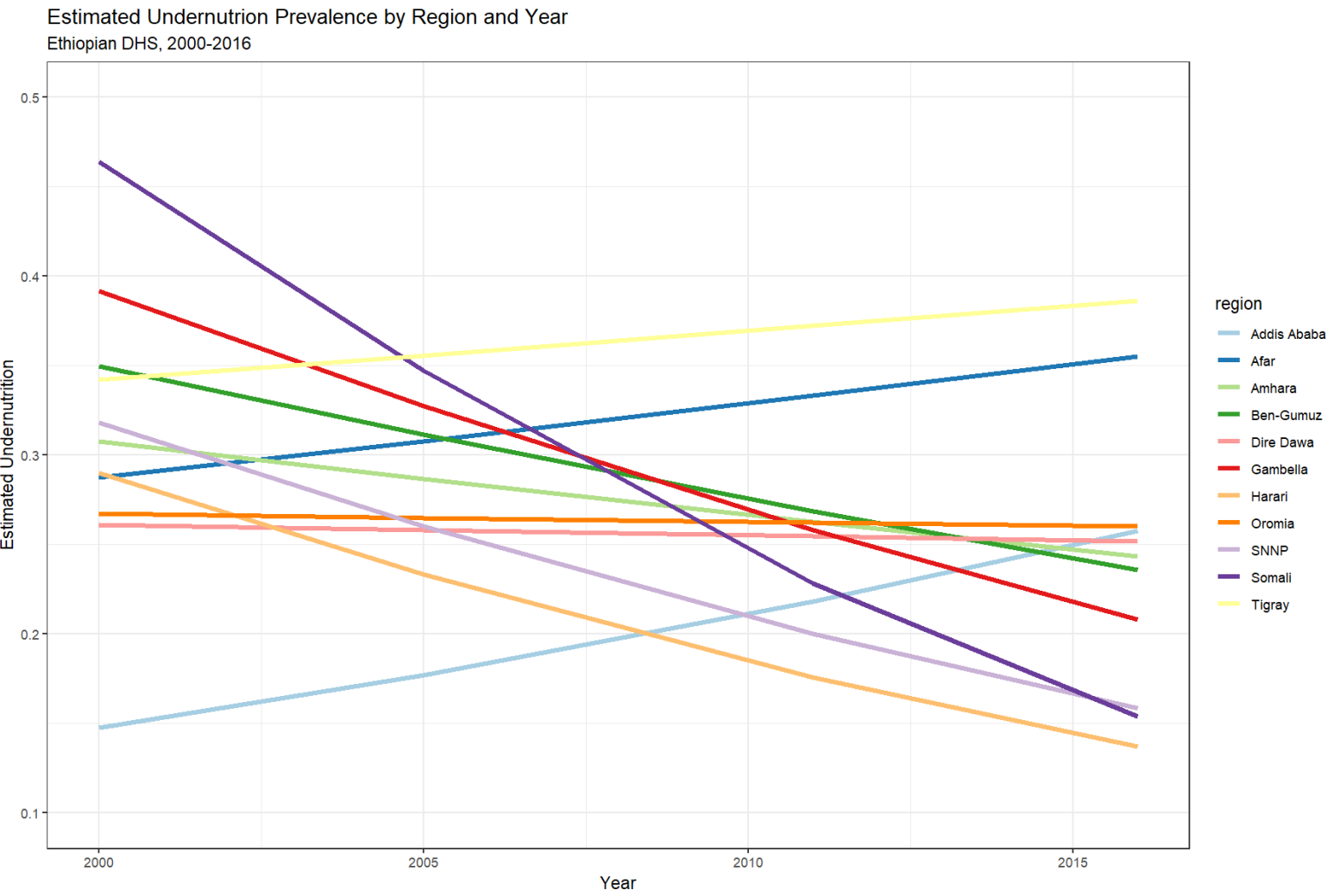

Figure 2: Trends in the proportion of women's undernutrition by region (EDHS 2000-2016)

Between 2000 and 2016, Tigray, Addis Ababa, and Afar regions show overall increases in the rate of undernutrition. Somali shows the greatest reduction in the rate of undernutrition, going from approximately $45 \%$ of women being undernourished to approximately $15 \%$ by 2016 . Regions also showing reductions include Gambela, SNNP, Amhara, Ben-
Gumuz, and Harari. Little or no change in women's undernutrition was observed in Oromia and Dire Dawa for the study period.

Model 2 controls for sociodemographic characteristics of women. In this model, the overall time trend becomes significant at the 10\% level, indicating a national level overall decrease over time 
in the rate of undernutrition. Regarding the individual level variables, age had a significant effect on women's undernutrition, with the odds of undernutrition reduced significantly as the age of women increases albeit the reduction in odds for women up to age 40-49. Women aged 20-29 were $37 \%$ less likely and women aged $30-39$ were $28 \%$ less likely to experience undernutrition compared with women aged 15-19. Parity status had no association with undernutrition in this analysis. Marital status also had a significant effect on women's undernutrition, with married women having 33\% lower odds while divorced or separated women had $27 \%$ lower odds of undernutrition compared with never-married women. The educational attainment of women also had a significant effect on undernutrition, with women who had secondary education having $16 \%$ lower odds of being undernourished, but no significant benefit was found for highly educated women. Women having primary education, however, had $6 \%$ higher odds of undernutrition compared with those who had no education. The household wealth index had a significant effect on women's undernutrition, with women from middle and high wealth households having $8 \%$ and $30 \%$ lower odds of undernutrition compared with women from poor households. Also, occupational status affected undernutrition significantly, with women who had a manual labor job had $16 \%$ lower odds while women who had a nonmanual job had 13\% lower odds of undernutrition compared with unemployed women. Finally, women residing in urban areas had $27 \%$ lower odds of undernutrition, compared to women in rural areas. Model 2 shows a reduction in the amount of between region variance and a reduction in the amount of variation in the time trend across regions. This suggests that women's characteristics are accounting for some of the differences both across regions and across time.

Model 3 shows very similar results to Model 2, indeed all the significant associations were maintained even after controlling for the region-level predictor. The overall time trend remains marginally significant. With respect to the regional variable, women residing in regions with higher levels of educated women had lower odds of being undernourished, compared to women in regions with average levels of education. The between region variance term remained like that from Models I and 2, while the variation in slopes between regions was further diminished, suggesting that the regional education variable is accounting for some of the differences over time between regions in the analysis.

\section{Discussion}

The current study presents results from a nationally representative sample of women in Ethiopia using four representative demographic and health surveys focusing on the impact of sociodemographic characteristics. The study shows mixed results in terms of improvement in women's undernutrition in Ethiopia over the period. While some regions such as Ben-Gumuz, Gambela, SNNP, and Somali, Harari and Amhara have seen consistent improvement over the study period, others such as Tigray, Afar and Addis Ababa showed overall increases in undernutrition over the period of the study. Afar's worsening conditions over the study period may be attributable to previous drought episodes that happened in that region during this period. It is estimated that about 655,000 pastoral community members were affected with limited access to healthcare in the Afar and Somali regions (FAO, 2016). For SNNP, the consistent improvement may be due to increasing trends of average food crop yields at all levels in the region over time (Cochrane \& Bekele, 2018).

Furthermore, the regression analysis shows that several individual-level sociodemographic characteristics and some aggregate factors have a significant effect on the regional variations in women's undernutrition in Ethiopia. The age of women has a significant relationship with women's undernutrition in the country. Women aged 20-39 are less likely to be affected by undernutrition than women aged 15-19, but the risk of undernutrition seems to increase after age 39. Adolescent girls are usually believed to be affected by sociocultural norms which negatively influence their health and nutritional well-being (Christian \& Smith, 20I8). In Ethiopia, this may be that some adolescent girls suffer food insecurity they are responsible for providing their family's daily nutritional needs.

Additionally, the risk of women's undernutrition is significantly associated with the educational attainment and employment status of women. The study finds that women with a secondary or higher education level face a lower risk of undernutrition. On the contrary, women without formal education have a higher risk of undernutrition. Research has strongly linked women's undernutrition to educational attainment (Hasan et al., 2017) and it has become obvious that women who have no formal education are deprived of the necessary socioeconomic resources that serve as a protective factor against many health conditions including undernutrition. Thus, the educational attainment of women in Ethiopia strongly defines their access to resources and exposure to food insecurity. This argument is strongly supported at both the individual level and the regional level as found in the regression 
model. The study findings further indicate that marital status considerably affects the nutritional status of women in Ethiopia. Married women, widows, separated or divorced women all have low risks for undernutrition in the country than never-married women. Thus, women who have never been married have the highest risk for undernutrition in Ethiopia (Girma \& Genebo, 2002). This finding is consistent with that of a study in Tanzania where unmarried women have been found to be more likely to be undernourished (Mtumwa et al., 20l6). This may well be that Ethiopian women who have never married may lack a source of economic support which may expose them to food insecurity, unlike the ever-married women who have ever received support from their partners.

In this study, the household wealth index also appeared to be a significant determinant of women's nutritional status in Ethiopia. Expectedly, women from poorest households were at the highest risk of undernutrition compared with their counterparts from wealthy households. A number of other studies have also shown some evidence that the risk of women's undernutrition increases significantly with the decrease in wealth status of women (Mtumwa et al., 2016). Predictably, women from poor households may experience a substantial dearth of resources which may, in turn, make them vulnerable to food insecurity. The effect of women labor force participation on women's undernutrition has also manifested in this analysis. Ethiopian women who have no job have a substantially increased risk for undernutrition than their counterparts who are employed in any sector of the country. Food insecurity which may usually lead to undernutrition is said to be higher among households headed by unemployed people in Ethiopia (Etana \& Tolossa, 2017). Similar studies elsewhere also provide evidence that non-participation in the labor force by women increases their risk for undernutrition (Bhandari et al., 2016). Unemployed Ethiopian women may be vulnerable to undernutrition because it may be difficult for them to afford adequate nutritious meals per day especially in settings where the cost of food is high. Finally, residential status has had a significant effect on women's undernutrition in this study, with rural women having increased risk of undernutrition than urban women in Ethiopia. In the same vein, a study using DHS dataset of 26 subSaharan African countries, has also indicated that rural women are more likely to experience undernutrition compared with their urban counterparts (O. A. Uthman \& Aremu, 2008). Undernutrition, thus, has a serious implication for Ethiopian rural women. This may well be due to disparities in socioeconomic conditions between these two settings. Also, some cultural factors such as those that dictate to people what to eat or not to eat and at which period they should be eaten or not to be eaten (Seleshe et al., 20l4) can also become an important factor for the nutritional disadvantage of Ethiopian rural women.

\section{Conclusions}

The findings of this study show that there are substantial regional disparities in women's undernutrition in Ethiopia over the study period. The pattern of regional variation in women's undernutrition in the country over the study period has, therefore, produced mixed outcomes. The spatio-temporal variations in women's undernutrition are affected by both changing characteristics of women, but also by the increases in women's education over time. Consequently, younger women without formal education, never-married, unemployed, and rural women, as well as women from poor households, have shown advanced risks for undernutrition than their counterparts. The policy implication is that these should serve as the risk factors upon which relevant policy decisions and interventions should be based or targeted. This study faces several limitations. We use repeated crosssectional data instead of truly longitudinal data, which would have been better. Secondly, our associations noted in the manuscript are descriptive and imply no causality.

\section{Conflict of Interest}

The authors declare that there is no conflict of interest regarding the publication of this paper.

\section{Acknowledgments}

Data for this study were obtained from the DHS Program.

\section{References}

Adedini, S. A. et al. (20/5). Regional Variations In Infant And Child Mortality In Nigeria: A Multilevel Analysis. Journal of Biosocial Science, 47(02), 165187. doi: 10.1017/S0021932013000734.

Ahmed, T., Hossain, M., \& Sanin, K. I. (20I2). Global burden of maternal and child undernutrition and micronutrient deficiencies. Annals of Nutrition and Metabolism, 6I(Suppl. I), 8-I7.

Babalola, S. (2017). Weight abnormalities among Nigerian women: correlates and programmatic implications. African Population Studies, 3I(I), 3478-3489.

Barba, C., Cavalli-Sforza, T., Cutter, J., \& DarntonHill, I. (2004). Appropriate body-mass index for Asian populations and its implications for policy 
and intervention strategies. The lancet, 363(9403), I57-I63.

Bhandari, S., Sayami, J. T., Thapa, P., Sayami, M., Kandel, B. P., \& Banjara, M. R. (20/6). Dietary intake patterns and nutritional status of women of reproductive age in Nepal: findings from a health survey. Archives of Public Health, 74(I), 2.

Bitew, F. H., \& Telake, D. S. (20I0). Undernutrition among women in Ethiopia: rural-urban disparity. DHS Working Papers No. 77. Calverton, Maryland, USA: ICF Macro.

Black, R. E., Victora, C. G., Walker, S. P., Bhutta, Z. A., Christian, P., De Onis, M., . . . Martorell, R. (20I3). Maternal and child undernutrition and overweight in low-income and middle-income countries. The Lancet, 382(9890), 427-45I.

Black, S. E., Devereux, P. J., \& Salvanes, K. G. (2005). The More the Merrier? The Effect of Family Size and Birth Order on Children's Education. The Quarterly Journal of Economics, I20(2),669-700.

Bürkner, P. C. (2017). brms : An R Package for Bayesian Multilevel Models Using Stan, Journal of Statistical Software, 80(I), I-28.

Caputo, A., Foraita, R., Klasen, S., \& Pigeot, I. (2003). Undernutrition in Benin-an analysis based on graphical models. Social Science \& Medicine, 56(8), |677-|69|.

Carpenter, B. et al.(2017). Stan : A Probabilistic Programming Language. Journal of Statistical Software, 76(I), I-32.

Chowdury, M. R. K. et al. (20/6). Risk Factors for Child Malnutrition in Bangladesh: A Multilevel Analysis of a Nationwide Population-Based Survey. The Journal of Pediatrics, I72, I94-20I.

Christian, P., \& Smith, E. R. (20|8). Adolescent Undernutrition: Global Burden, Physiology, and Nutritional Risks. Annals of Nutrition and Metabolism, 72(4), 316-328.

Cochrane, L., \& Bekele, Y. W. (2018). Average crop yield (200I-20I7) in Ethiopia: Trends at national, regional and zonal levels. Data in brief, 16, 10251033.

CSA, \& ICF. (20I2). Ethiopia demographic and health survey 2011. Addis Ababa, Ethiopia and Calverton, Maryland, USA: Central Statistical Agency and ICF International.

CSA, \& ICF. (2016). Ethiopia Demographic and Health Survey 2016. Addis Ababa, Ethiopia, and Rockville, Maryland, USA: CSA and ICF.

Etana, D., \& Tolossa, D. (20I7). Unemployment and food insecurity in urban Ethiopia. African Development Review, 29(I), 56-68.

Fanzo, J. (2012). The nutrition challenge in subSaharan Africa. Working Paper 20I2-0I2. United Nations Development Programme, Regional Bureau for Africa.
FAO. (2016). FAO Emergencies Director assesses the scale of the drought and response in Afar Region, Ethiopia.www.fao.org/resilience

/newsevents/detail/en/c/44633I/. Accessed $01 / 03 / 2019$

FAO, WFP, \& IFAD. (20I2). The state of food insecurity in the world 20I2. Economic Growth is necessary but not Sufficient to Accelerate Reduction of Hunger and Malnutrition. Rome, FAO, I-6I.

Ferede, A., Lemessa, F., Tafa, M., \& Sisay, S. (2017). The prevalence of malnutrition and its associated risk factors among women of reproductive age in Ziway Dugda district, Arsi Zone, Oromia Regional State, Ethiopia. Public Health, 152, I-8.

Gedle, D., Gelaw, B., Muluye, D., \& Mesele, M. (2015). Prevalence of malnutrition and its associated factors among adult people living with HIV/AIDS receiving anti-retroviral therapy at Butajira Hospital, southern Ethiopia. BMC Nutrition, I(I), 5.

Gelman, A. (2004). Parameterization and Bayesian Modeling. Journal of the American Statistical Association, 99(466), 537-545.

Gelman, A., Lee, D., \& Guo, J. (2015). Stan: A Probabilistic Programming Language for Bayesian Inference and Optimization. Journal of Educational and Behavioral Statistics, 40(5), 530-543.

Gelman, A., \& Rubin, D. B. (1992). Inference from Iterative Simulation Using Multiple Sequences. Statistical Science, 7(4), 457-5I I.

Gelman, A., Simpson, D., \& Betancourt, M. (2017). The Prior Can Often Only Be Understood in the Context of the Likelihood. Entropy, 19, 555.

Girma, W., \& Genebo, T. (2002). Determinants of nutritional status of women and children in Ethiopia. Calverton, Maryland, USA: ORC Macro.

Habyarimana, F., Zewotir, T., \& Ramroop, S. (20I5). Analysis of demographic and health survey to measure poverty of household in Rwanda. African Population Studies, 29(I), I472-1482.

Haile, D. et al. (20|6). Exploring spatial variations and factors associated with childhood stunting in Ethiopia: spatial and multilevel analysis. BMC Pediatrics, I6(I), 49.

Hasan, M., Sutradhar, I., Shahabuddin, A., \& Sacker, M. (20I7). Double Burden of Malnutrition among Bangladeshi Women: A Literature Review. Cureus, 9(I2), el 986.

Hong, R., \& Hong, R. (2007). Economic inequality and undernutrition in women: multilevel analysis of individual, household, and community levels in Cambodia. Food and Nutrition Bulletin, 28(I), 5966.

Jolliffe, I. T., \& Cadima, J. (2016). Principal component analysis: a review and recent 
developments. Philosophical Transactions. Series A, Mathematical, Physical, and Engineering Sciences, $\quad 374(2065), \quad 20150202$. doi: $10.1098 /$ rsta.20I5.0202

Kamal, S., \& Islam, A. (20|0). Socio-economic Correlates of Malnutrition among Married Women in Bangladesh. Malaysian Journal of Nutrition, 16(3), 349-359.

Lartey, A. (2008). Maternal and child nutrition in SubSaharan Africa: challenges and interventions. Proceedings of the Nutrition Society, 67(I), 105108.

Mohsena, M., Goto, R., \& Mascie-Taylor, C. (2015). Regional variation in maternal and childhood undernutrition in Bangladesh: evidence from demographic and health surveys. WHO SouthEast Asia J Public Health, 4(2), I39- I49.

Mtumwa, A. H., Paul, E., \& Vuai, S. A. (2016). Determinants of undernutrition among women of reproductive age in Tanzania mainland. South African Journal of Clinical Nutrition, 29(2), 75-8I.

Mukuria, A., Aboulafia, C., \& Themme, A. (2005). The context of womens health: results from the Demographic and Health Surveys 1994-200I. Calverton, MD, ORC Macro.

$\mathrm{R}$ Core Team and $\mathrm{R}$ Development Core Team. (2018). R: A Language and Environment for Statistical Computing. Vienna, Austria: R Foundation for Statistical Computing. Available at: www.r-project.org.

Sahn, D. E. \& Alderman, H. (1998). Nutritional Status and Poverty in Sub-Saharan Africa. Africa Region
Findings and Good Practice Infobriefs No. 108. Washington, DC: World Bank.

Sharma, R., Gaffey, M. F., Alderman, H., Bassani, D. G., Bogard, K., Darmstadt, G. L., . . Bhutta, Z. A. (2017). Prioritizing research for integrated implementation of early childhood development and maternal, newborn, child and adolescent health and nutrition platforms. Journal of Global Health, 7(I), 011002 . doi: I0.7I89/jogh.07.01 I 002

Seleshe, S., Jo, C., \& Lee, M. (20|4). Meat Consumption Culture in Ethiopia. Korean Journal for Food Science of Animal Resources, 34(I), 713.

Tebekaw, Y., Teller, C., \& Colón-Ramos, U. (20/4). The burden of underweight and overweight among women in Addis Ababa, Ethiopia. BMC Public Health, I4(I), II 26.

Uthman, O. A. (2009). Patterns, distribution, and determinants of under-and overnutrition among women in Nigeria: a population-based analysis. Journal of Public Health, I7(5), 289-299.

Uthman, O. A., \& Aremu, O. (2008). Malnutrition among women in sub-Saharan Africa: rural-urban disparity. Rural and Remote Health, 8(2), 93I.

$\mathrm{Wu}, \mathrm{X}$. \& Li, L. (20/2). Family size and maternal health: evidence from the One-Child policy in China. Journal of Population Economics, 25(4), |34|-| 364 . 